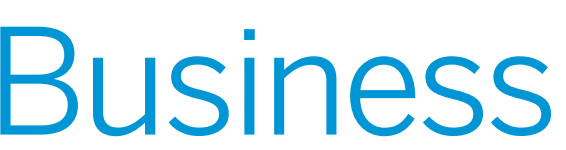

6832018 Teaching \& Learning Conference Track Summaries

695 114th Annual Meeting Information

696 Meet the 2018-19 APSA RBSI Scholars

7002018 APSA Council and Officer Nominees
705 Next in $P S$

705 Call for Submissions

706 Washington Insider

707 Members of the Month

709 International

710 Gazette

\title{
2018 Teaching \& Learning Conference Track Summaries
}

$\mathrm{T}$ rack summaries of the seven tracks at the 2018 Teaching and Learning Conference, which took place February 2-4 in Baltimore, MD, are published in the following pages. These summaries include highlights and themes that emerged from the research presented in each track. The summary authors also issued recommendations for faculty, departments, and the discipline as a whole-providing suggestions for new strategies, resources, and approaches aimed at advancing political science education throughout the discipline and beyond. For more information on the 2018 Teaching and Learning Conference, including award winners, refer to PS's April 2018 issue.

\section{Civic Engagement Education: Foundations}

\author{
J. Cherie Strachan, Central Michigan University \\ Margot Morgan, Indiana University, Southeast \\ Ruxandra Paul, Amherst College
}

This year, once again, civic engagement tracks attracted the highest number of participants at APSA TLC. The foundations track generated thought-provoking discussions about the role of civic engagement teaching and learning in political science. Collectively, we addressed a range of pressing questions: Can and should political scientists teach civic engagement in the classroom? Is it possible to teach civic engagement in an inclusive, unbiased way (can civic and political engagement be disentangled)? Do civic engagement teaching methods and practices generate learning opportunities that are truly open to all students or are they unintentionally excluding those who, arguably, would benefit from them the most? Should civic engagement teaching and learning happen in the curriculum (course requirements) or is it more fruitful to pursue civic engagement as a cocurricular activity without any course credit granted towards a political science major? Can civic learning outcomes be evaluated? Are teaching strategies that allow quantification desirable, despite the limits that quantifiability places on the range of possible activities? What is the role of the professor in civic engagement instruction? How can on-campus and off-campus activities be combined to produce coherent learning experiences? What can we learn from other disciplines? What tools can we borrow?

Participants analyzed methods and contexts for civic engagement on and off campus. They thought about how to develop stronger assessment tools and best practices. While some presenters focused on civic engagement within political science, others looked at civic engagement activities that are independent of political science departments. Still others discussed the importance of interdisciplinary and cross-disciplinary cooperation, arguing for the need to view civic engagement as a university- and college-wide priority and integrate the work of political science departments with that of other departments, campus organizations, and off-campus community partners (government institutions, nongovernmental organizations, political parties, etc.).

\section{SUMMARY OF PANELS}

Our presenters were largely interested in designing and assessing activities and interventions that would promote civic engagement at undergraduate institutions. Many offered examples of innovative strategies and pedagogical tools, while others discussed course designs and more traditional strategies. The importance of assessment was a recurring theme, most directly addressed by Bennion in her discussion of assessment tools and best practices for measurable learning outcomes. There was a consensus that discussions of civic engagement would be more persuasive the more solid assessment data we have at our disposal. Yet, there was an awareness that some aspects of civic engagement education (critical thinking or disorienting students to encourage deeper questioning) remain difficult to measure.

Some presenters examined specific inclass activities designed to increase student civic engagement. Mueller discussed how designing, conducting, and interpreting political surveys helped students understand and overcome stereotyping. In her course, students were asked to construct survey questions that gathered demographic information and the respondents' political views. Before administering the survey to other members of the university community, the students were also asked to predict how members of various social groups would respond to the political questions. The results defied many of the students' expectations. This led to a discussion of stereotypes and their impact on trust, tolerance, and social capital in our political community. 
A second group of presenters discussed the value of civic engagement initiatives and teaching formats, tools, and technologies that combine on-campus and off-campus elements. Fitzpatrick discussed the pedagogical possibilities of PhotoVoice, an application that allows students to construct narratives out of photographs that they take in their daily lives. PhotoVoice has already been used in psychology and public health education with some level of success. Hoffman presented an internship program at the Maryland General Assembly that combines interning two to four days per week in Annapolis with weekly on-campus seminar meetings. He found that students who interned demonstrated increased levels of political efficacy and political knowledge in their posttests. Paul talked about a political science course offered at Amherst College that meets in a local prison and in which half of the participants are college students and the other half are inmates. Bennion mentioned the benefits of combining political science instruction with journalism, when her students interviewed candidates for local, state, and national elections for a live weekly television program called Politically Speaking.

A third group of presenters emphasized the importance of civic engagement initiatives that occur outside the classroom and independently from it (noncourse activities that receive no course credit). RodriguezFarrar of Dominican University of California discussed the impact of College Debate 2016 on her campus. Dominican was chosen by the Commission on Presidential Debates to host student delegates representing 150 college campuses from across the country, who used social media and technology, in addition to caucus- and townhall-style deliberation, to formulate questions about issues that matter to young voters and submit them as proposed questions to be asked at the presidential debates in 2016. Interestingly, the college's participation in the initiative had nothing to do with their political science department, nor were the student delegates who participated predominantly political science majors. Rodriguez-Farrar, the senior assistant to the president of Dominican, discussed College Debate 2016 as an example of the importance of making civic engagement a campus priority, rather than a priority of political science departments. She stressed the importance of student engagement (telling their story, interviewing others, sharing content on social media, etc.) and the appeal of new technology in maximizing visibility and impact. Many aspects were gamified. Students took the lead and taught each other; none of the activities involved professors talking at students.

The premise that we need to look beyond an individual class or activity is at the core of other presenters' work. Abernathy and Forestal assessed the political science curriculum at their institution, Stockton University, and looked at eight courses over three semesters to measure civic learning outcomes. They found that, taken as a whole, these department courses increased students' levels of political efficacy, knowledge, and skills associated with civic engagement. At the same time, they highlighted variation in outcomes and emphasized the need for more data.

In a comparative study of curricula, resources, recent course offerings, and teaching practices in the Five College Consortium (Amherst College, Smith College, Mount Holyoke College, Hampshire College and University of Massachusetts, Amherst), Paul examined the disciplines in which civic engagement education occurs to study, in context, the contribution of political science departments. She found that, while all political science departments taught some courses on civic engagement, their approaches varied depending on institutional culture. The variation was reflected in terms used by faculty to refer to this work: some used "civic engagement" as a term, but others preferred "community-based learning," "service learning," "public engagement" and "politicizing." Paul also noted (and track participants concurred) that political science appears to be lagging behind other disciplines and departments (sociology, anthropology, American studies, etc.) when it comes to emphasizing the importance of civic engagement.

\section{CALL TO ACTION}

Our track expressed concern that political science is behind the curve relative to other disciplines in terms of developing and supporting civic engagement. One reason for this is that civic engagement activities by faculty members are not seen by administrators as valuable: promotion and tenure requirements are still too rigid at most institutions. Faculty focusing on traditional research and teaching activities do not have the resources to devote to service learning, civic engagement, or other innovative practices. Another reason why political science may be lagging behind has to do with the discipline's vision of itself as a social science, that is, as an objective mode of inquiry that is ideally value free. The decision to promote democratic values may be seen as anti-scientific.

This track urges political science departments-and political science as a discipline-to reevaluate its relationship to democratic values and civic engagement. Political science cannot be objective if it wishes to be relevant. We argue that civic engagement should be part of our mission as a discipline-that we should embrace our role as activists for democracy, broadly understood. This is not to say that we should tout specifically liberal or progressive causes-we should instead try to make all students, regardless of their party affiliation or political leanings feel included. We need to openly embrace and promote democratic values and activities.

Our track also urges colleges and universities to institutionalize civic engagement, making it a part of every student's educational experience. Rather than viewing civic engagement as limited to one or two political science courses, administrators need to offer civic engagement opportunities to students throughout their college careers. Those opportunities should exist both inside and outside the classroom, in a variety of contexts and involving a variety of content. A key component of this approach is the coordination among academic affairs personnel and the personnel involved in student affairs. Another key component is the recognition and reward of civic engagement work done by faculty. Without that, political scientists and other faculty members are faced with disincentives to perform this important work. In such contexts, there may be the occasional faculty champion who does civic engagement work out of love; but without institutionalization and a strong incentive structure, when that champion leaves, the project will most likely die.

Finally, our track wishes to emphasize the importance of inclusivity. Civic engagement opportunities should be open to all of our students. We need to be mindful of the fact that nontraditional students, first-generation students, and students of low socioeconomic backgrounds may be coming to the university with lower levels of civic engagement, self efficacy, and political knowledge than their peers. These students are the ones we most need to reach and the ones for whom civic engagement activities can have the biggest impact. 


\section{Civic Engagement Across The Disciplines And Across Campus}

\author{
Laura Roost, Newberry College \\ Lynne Chandler Garcia, US Air Force Academy
}

Techniques to engage students in politics and civic participation were the theme of this year's civic engagement track. Scholars representing private and public four-year degree institutions, community colleges, military academies, and international institutions as well as practitioners from a variety of organizations and programs met to present and discuss new ideas relating to civic engagement. Ten papers were presented over four panels in an open and constructive dialogue. Ideas proposed included service learning projects, interdisciplinary approaches, field work, and utilizing campus and national institutes to support civil learning, among a host of other novel ideas. Discussion revolved around the definition of civic engagement, the need for data to drive analysis of engagement efforts, and the role of political scientists as well as practitioners in fostering civic engagement efforts.

\section{CIVIC ENGAGEMENT EDUCATION ACROSS THE CURRICULUM}

The first presentation focused on the need to include civic engagement across the curriculum and throughout multiple disciplines. Surak and Hall presented findings gleaned from a series of evening lectures hosted by an interdisciplinary core of faculty. The lecture series was a race and identity course, administered as a pass/fail, one-credit option for students. The experiment proved to be a novel way of engaging students through a multidisciplinary approach. Discussion centered on the logistics and curriculum challenges involved in using interdisciplinary approaches for fostering civic engagement.

With campuses playing important roles in fostering civic competence and political skills, Matto and McHugh presented their research on campus-based political engagement centers and institutes. An exploration of these centers revealed a number of unanswered research questions such as what types of campus activities are most effective in promoting civic engagement, and how do centers promote these activities? The most important question raised by the research concerned the role of political science departments and faculty in working with and assessing centers. These questions are fodder for further study on this topic, and the authors presented several possible paths for future research.
The third paper in this forum, presented by Eichbaum, focused on embedding civic engagement curriculum on a "whole-ofuniversity" basis. Eichbaum conducted his research at Victoria University in New Zealand where all universities have a national, constitutionally based obligation to serve as a "critic and conscience" while promoting civic discussion and engagement. Further, civic engagement education promotes employability for students, and thus is desired and promoted within curriculums in New Zealand schools. As the merits of this work were shared, attendees discussed the need for comparative approaches on civic engagement work and ways to share best practices among schools located across the United States and throughout the world.

Ideas gathered from the first panel revolved around improving strategies for including civic engagement within curriculum. Civic engagement should be promoted as a whole-of-curriculum challenge, rather than being viewed as primarily the responsibility of the political science discipline. Further, while scholars and practitioners seek to promote civic engagement across the curriculum, there is a need to create institutional linkages in which scholarship and techniques can be shared and improved upon. Political and civic engagement projects, especially those that take place outside of the classroom, can have a large impact on the surrounding community. Scholars must build true partnerships with community organizations to ensure projects build rather than hinder cooperation. As research on civic engagement techniques improves, and data is increasingly collected, scholars must be aware that curriculum activities can be sensitive, and Institutional Review Board (IRB) requirements for human subjects should be carefully considered.

\section{CIVIC ENGAGEMENT EDUCATION ON CAMPUS}

The second panel featured techniques to engage a diverse student population while navigating the complexities of upholding free speech and academic freedom in today's political environment. Thomas began her presentation by reminding participants that higher education has an interest in promoting inclusion and free speech as part of a politically-engaged campus. The First Amendment provides guarantees of free speech, and it also provides the basis of academic freedom. In addition to protecting speech within the classroom, we must consider other public spaces such as dormitories, quads, and even roadways as physical spaces on campus where free speech should be protected. These public spaces are the next challenge as universities grapple with free speech and academic freedom issues.

Promoting free speech and political participation is complicated for most colleges and universities; these imperatives are even more challenging in a military institution where regulations govern the speech and action of active duty service members and defense civilians. Chandler-Garcia focused on these challenges in the effort to promote civic engagement among cadets at the US Air Force Academy where building leaders of character and promoting engaged citizenship is an imperative. Several strategies were discussed including promoting classroom discussion and service learning options. Discussion turned to the importance of creating inclusive environments for all veterans, as students with military backgrounds have increasingly become part of the student population at most universities and colleges.

Mueller wrapped up the session by exploring the effects of using off-campus activities in New York City to promote civic and political engagement among first-year students. Students in the experiment group took part in field trips, experiential learning opportunities, and had classroom speakers with a focus on building relationships amongst their peers and with faculty in addition to familiarizing them with the city. Pre- and post-survey results revealed some increase in intention to participate in future political and civic activities, increases in willingness to read about political issues, and an interest in using the performing arts to illustrate political issues. Discussion centered on future longitudinal studies to measure the longterm effects of such activities and studies comparing groups focused on local versus global issues.

This panel focused on the sometimes perilous ground educators must navigate while promoting free speech, open political dialogue, and academic freedom within an 
environment that often seeks to tamper campus speech on controversial political issues. There is a need to hear diverse voices and multiple perspectives on campus but also celebrate diversity and maintain inclusivity. As political scientists, we must consider the goals of political engagement, the metrics we can use to measure these outcomes, and the data we are using to ensure we are truly assessing our stated learning objectives.

\section{EVALUATING SERVICE-LEARNING OUTCOMES}

The third panel examined ways to evaluate service-learning outcomes. Blair and Charlton started the panel by considering the effectiveness of service-learning to building traditional learning outcomes, while also building social capital and political engagement. The project connected students with organizations such as the Square Mile program, where students supported cancer patients and worked in migrant and refugee communities. A total of $93 \%$ of participants said their communication skills improved due to their service learning, and Blair and Charlton posit that service-learning helped students build relationships with the community and each other. At the same time, students expressed that their primary interest in service learning was as experience for future employment rather than altruism. Still, Blair and Charlton indicated course learning outcomes were amplified due to the service-learning.

Next, Harding described her policy class in which students completed service with an agency associated with the policy area they were researching for their class paper. Her pre- and post-test responses from students highlighted the value of service-learning: $82 \%$ said they felt more connected to the agency, $55 \%$ said they had interest in future servicelearning, and $82 \%$ reported a better understanding of applications for policy research. Of particular interest was the result of Harding's Wilcoxon signed-rank test which found critical thinking to be the significant variable.

These papers prompted a lively discussion about the need to measure the effectiveness of service-learning and understand the impacts service-learning has on applying classroom knowledge as well as critical thinking, social capital, and other life skills. A common concern about service-learning was the difficulty knowing what to expect from service-learning experiences, and whether service-learning is better suited for lower or upper level courses. The idea of laddering service-learningmeaning students would build on their service learning skills through opportunities which matched the progression of their courses from general to more specific workwas put forward as a way to make sure that service-learning was guided and provided curricular and personal knowledge.

\section{COMMUNITY-BASED LEARNING \& RESEARCH}

The final panel looked at more in-depth variations of community-based learning. Josephon and Gallagher discussed the concept of an "Outside In University" to highlight the importance of considering both the community and the classroom as sites oflearning. As students helped individuals facing eviction or facilitated reunification visits of separated families, they gained unique insights on what it means to be a citizen. Josephon and Gallagher emphasized the importance of university support for community-based learning, which in turn made it easier for faculty to commit to community-university collaboration.

Glober, Cole, and Owens shared their experiences with the ENACT (Educational Network for Active Civic Transformation) program. ENACT Faculty Fellows help students become politically engaged by connecting with their state legislatures. This gives students an understanding of the practice of politics, the work that goes into policy advocacy, and the professionalism needed for interaction with political officials. Embedding these opportunities in classes means that students go beyond a one-time speaking event with a state legislator, for example, to understanding more about the work of political staff, the interactions between the public, the staff, the legislator, and the legislature, and the process of advocacy.
Looking at ways to include service-learning and community-based learning in courses provided opportunities to dig deeper into the value of service-learning and civic engagement. Most importantly, through this panel we were able to take lessons from facilitating and measuring the effectiveness of this pedagogical approach while thinking about ways to more deeply connect with the community in ways that benefit the community and our students.

\section{CONCLUSION}

This track provided a forum to discuss the meaning and importance of civic engagement, in its many forms, within the discipline of political science as well as across curriculum. There is a need to define civic engagement and explore the objectives of engagement education in terms of political participation, civic virtue development, and community building. As these layered meanings are explored, political scientists must consider if their roles should be as owners of the process, partners, facilitators, or guides. Rather than viewing political science as the discipline that "owns" civic engagement, curriculum development should be cross disciplinary, and should include international perspectives as well as first-year experiences, community college perspectives, and other institutional viewpoints. We need to create a community and a space where we can share ideas, assessments, rubrics, and curriculum best practices.

Research continues to improve as we link civic engagement practices and community-based learning programs to methodology. We need to collect solid data for measuring civic engagement models, utilize longitudinal models and comparative perspectives, and share models with fellow researchers. As we continue to engage in this research, scholars require institutional support from university and college leadership and administrators who understand the importance of, and encourage, civic education within classrooms, throughout campuses, and within the surrounding community. 


\section{Disciplinary Curriculum And Assessment}

\author{
Chad Kinsella, Ball State University \\ Bobbi Gentry, Bridgewater College \\ Erin Rowland, University of Tennessee, Knoxville \\ Kelebogile Zvobgo, University of Southern California \\ Megan Becker, University of Southern California
}

Diversity, equity, inclusion, and access have emerged in recent years as institutional priorities in academia and in industry. Colleges and universities increasingly recruit individuals from underrepresented and underserved groups, such as women, first-generation college students, people of color, and individuals from an array of backgrounds. Yet, both institutions of higher learning and industry scarcely reflect the demographic makeup of the communities in which they operate and the United States more generally. Recruitment of diverse talent has improved, but the "pipeline problem" persists. But, why? The papers presented in the Disciplinary Curriculum and Assessment track at the TLC illuminated two dimensions of the pipeline problem and responded with a variety of innovative pedagogical practices. Six enduring themes persisted throughout the track and include: Reducing barriers and increasing access, macro versus micro assessments, trust as a necessary component to teaching and learning, evaluations of teaching and learning are often performance rather than process based, development of better assessments of student learning has outpaced assessments of teaching, and cost directly impacts curricular choices.

\section{AN INTEGRATED APPROACH TO ADDRESSING THE PIPELINE PROBLEM}

Higher education has experienced the pipeline problem as two-dimensional. There exist both barriers to entry and barriers to retention, both in institutions of higher learning and industry. Thus, recruitment and admission of students from underrepresented groups is not the only strategy if we are to both fill and mend the leaky pipeline. A more integrated approach is required. The participants in the Disciplinary Curriculum and Assessment track hailed from small liberal arts colleges, large research universities, minority-serving institutions (MSI), and predominantly white institutions (PWI), each with its own sets of challenges and opportunities with respect to diversity. Despite these differences, the presentations and discussions demonstrated how we introduce students to political science, the curriculum we design for their learning, the manner and extent to which we train and mentor them, and the fairness with which we assess them are essential for cultivating and sustaining diversity, equity, inclusion, and access in undergraduate education.

\section{INTRODUCING STUDENTS TO THE POLITICAL SCIENCE CLASSROOM}

The Disciplinary Curriculum and Assessment track began with three studies of how students make the bridge from $\mathrm{K}-12$ to college and are introduced to the political science curriculum. As part of this transition, Rowland reports professors are inheriting new challenges from the modern secondary education classroom that has had to adapt to No Child Left Behind legislation, new teacher evaluation structures, and high school graduation rate mandates. Modern students are now used to fast-paced $\mathrm{K}-12$ environments with highly diversified instructional methods, student grouping, and technological mechanisms, and they are given multiple chances to turn in work late or retake tests. However, once students reach college, they are struggling to adapt to the accountability and demands of the university classroom.

Thus, to retain more at-risk students and help them overcome these challenges, some colleges have begun offering early start or bridge programs. For example, Herrera and Woodall relate how a two-week Arizona State University summer bridge program, modeled after Tinto's theory of student attrition, has been key in helping bring at-risk students up to par with other incoming freshmen in political science. Furthermore, participants in the program reported a greater sense of comfort with the college and departmental faculty, which is key for student retention. On the other hand, Hierman examines another facet of acquainting new students with the field. Particularly, Hierman questions how various departments introduce political science as a discipline and finds mandatory introduction courses, course objectives, and program requirements are far from universal. Thus, he suggests that there is much that could be gained by creating a core foundational introductory course in political science that would be required at most schools as part of a structured curriculum.

\section{CURRICULUM DESIGN AND HIGH- IMPACT PRACTICES}

Papers on these panels offered a variety of perspectives on experiential learning opportunities that, when carefully scaffolded, may help faculty retain majors and aid them in their educational development. A recurring theme amongst the papers was the use of high-impact practices, explained by George D. Kuh in "High-Impact Educational Practices," and how they might be integrated into curricula in a variety of institutional contexts. The panels also benefited from an international perspective, featuring papers that examined practices in the Netherlands and in France, respectively.

Scriven discussed strategies for "flipping the classroom" by integrating student-led debates into class time. By requiring that students argue from positions that are not their own, they gain experience with considering multiple points of view and refine their grasp of argumentation. Gentry examined the prevalence of required internships and the experiences and perceptions of faculty internship coordinators at community colleges. Survey respondents reiterated the importance and value of internship experience, while noting that these programs are frequently under-resourced. Becker and Zvobgo's paper discussed the opportunities provided by integrating research experiences into the curriculum and the ways in which these experiences can enrich the productivity and professional development of both students and faculty. They propose that these experiences can be scaled and made more accessible by using a team-based structure for research. They describe the activities of the Security and Political Economy Lab at the University of Southern California, where students participate in cutting-edge substantive research, while also gaining important project-management and leadership skills.

How do we assess these experiences and decide whether to make them a mandatory part of political science curricula? McClellan, 
Kopko, and Gruber assess a curricular change at Elizabethtown College, which now requires that students participate in a set number of high-impact practices. After collecting a panel of student survey data, they find that, while the learning outcomes achieved vary across the type of experience, participation in these activities generally contributes to student competency and satisfaction. Breuning continues the assessment conversation, showing how universities in the Netherlands use scaffolding of learning outcomes to guide both curriculum design and assessment. These learning outcomes are of particular interest because they not only deal with knowledge attainment, but a wide variety of research skills and professional development outcomes as well.

No matter their institutional context, the panelists demonstrated unique ways of engaging students in the classroom, through internships, and via research opportunities and highlighted opportunities to assess their effectiveness. Both in the US and abroad, students come to university with different backgrounds and varying levels of preparation. We must be thoughtful in designing a curriculum that guides students through their academic development, provides clear statements about learning outcomes and their value to the student, and assures that students have access to the appropriate resources to be able to participate fully in all components of the educational experience.

\section{ASSESSMENT OF STUDENTS AND FACULTY}

The final panel within the Disciplinary Curriculum and Assessment track addressed themes of grade reliability, student skewed assessment of good teaching, and the practice of grading better and more efficiently. The commonality of the three papers presented is that higher education relies on assessment. Professors must assess their students and assign grades, and students, in turn, assess their instructors to determine how well they feel the class was taught. Although the basis of assessment relies on it to be objective, in fact, there are many instances where it is subjective and, therefore, requires more scrutiny and study. Siver and Haeg's paper examines the literature regarding student evaluations of instructors and finds a preponderance of evidence suggesting a negative bias against women and people of color in teaching evaluations as well as propensity to confuse popularity with teaching. Their paper makes a crucial point about the subjective nature of student evaluations and the possible strong, negative effects they can have if not put into context. Rom's paper examines the essential element of grading with higher education.
The paper examines grading as a transaction between student and professor that is both market oriented and political and begins the task of investigating the broad array of tasks and interactions involved in grading in higher education. Finally, Kinsella's paper examines the grading criteria used to assess student writing. Using survey responses from students, the paper finds that students generally believe they deserve high grades and find marginal use of detailed grading criteria for the work they will turn in to be assessed.

\section{CONCLUSION}

The nature of curriculum and assessment in the discipline is both developed and developing. Curriculum and assessment are not new to the discipline, however, doing assessment for outside actors is. Just as trust is necessary in teaching and learning, trust is necessary within the curriculum and within assessment. The measures of both should be performance and process based. The view of an entire curriculum should include assessments that are macro and micro, just like we assess students. More work needs to be done on assessment of teaching. Diversity and inclusion are necessary elements of continuing to develop our faculty and students. Increasing access to political science and reducing barriers to access is critical for the future of the discipline.

\section{Liberal Arts}

\section{Luke C. Sheahan, Duke University}

Liberal education is a contested concept. What does it mean to be liberally educated? What is the relation between liberally educated citizens and the republican form of government? Does a liberal education require that teachers inculcate political virtues in their students, or refrain from doing so? To what extent is liberal education practical (as in moral or political) and in what sense is it restricted to the theoretical realm of contemplation and purely intellectual engagement? How do administrators, teachers, and students with different political commitments treat each other in the context of liberal arts classes?

The liberal arts track was organized to approach these questions from a variety of perspectives. Several themes emerged throughout the course of the day that demonstrated the relevance of the topic as well as the need for further inquiry. First, the education system is troubled and it is failing to educate its citizens in a fundamental way. Second, this failure has led to recent free speech controversies, political turmoil, and to the election of demagogues. Third, teaching for political citizenship is necessary, but there is little consensus as to the appropriate way to engage students for political action.

The first panel considered the role of liberal education in training for citizenship. While the panelists approached various aspects of the problem, what brought the papers together was a concern that the education system had distorted the proper education of citizens. Carol McNamara pointed out that a liberally educated populace would have rejected the demagogic overtures of Donald Trump and that the Trump election was evidence of a failure on the part of colleges and universities to properly educate citizens in civic virtues and civic duties. By the same token, the Trump election may be a "Sputnik moment," a realization of failure and an opportunity for a reorientation of educational priorities, which must include an education in political principles, such as the rule of law and natural rights. Paul Carrese likewise identified a decline in civic literacy as a failure of the education system. But he cautioned that a liberal education would need to ask "first order questions" rather than focusing exclusively on activism and civic engagement. Such a turn in education would include revamping the teaching of political science to study the constitutional views and political philosophy of the founders. Geoffrey Vaughan likewise faulted the current education system for a failure to liberally educate its students, but placed blame on the rise of identity politics which he described as anathema to a proper liberal education. Rather than emphasizing the common human elements at the heart of liberal education, identity politics establishes fixed points of difference around race and gender that make 
impossible a truly liberal education, one that educates for a common humanity.

While the first panel principally diagnosed problems with contemporary civic education, the second panel focused on a more precise definition of a proper political education. Steven McGuire discussed the difference between active and theoretical thought in Aristotle and related it to the difference between political and philosophical education. While the latter lifts one to the divine, the former is concerned with the merely human, with the art of compromise that makes one effective in human political community. R.J. Snell discussed the paradox of education for republican citizenship. A republic needs tradition to give it stability, but our republic was founded by a revolution and republican education must include inculcation of a willingness to rebel to preserve the republic from demagogues and tyrants. But this spirit of rebellion in turn undermines tradition and the long-term stability of the republic. An additional irony in training republican citizens is that they must be trained in liberty together, which requires a liberal education in a consistent curriculum of great books. William Werpehowski approached the specific question of how a Catholic university may train students for civic engagement. He argued that at the heart of a truly Catholic education is an ethic of nonviolence inherently opposed to the notion that war is an instrument of justice. This training puts its students at odds with economic and political elites, but citizens trained in that way leaven the republic with a love for truth, the poor, and their fellow citizens.
Turning to the subject of classroom teaching, the third panel addressed various ways that classroom pedagogy can enhance political education. Ajay Singh Chaudhary drew on his experience founding and teaching in the Brooklyn Institute for Social Research to describe the classroom as a safe space which enables teachers to hold conversations on hard issues. The point of teaching is not persuasion but providing pieces of knowledge and the time and space for students to put them together on their own. Lorraine McCrary discussed Michael Oakeshott to argue that teaching is a conversation, but even more than a conversation between different viewpoints, it is a discussion taking place between different modes of understanding. The form of Plato's dialogues is not just a means of contrasting different viewpoints, it is inextricably related to the content Plato explores.John-Paul Spiro wrapped up the session arguing that the classroom is a unique space to explore discredited ideas as a means to critique contemporary understandings of key concepts that students otherwise may take for granted.

Moving the discussion to contemporary controversies and concerns, the final panel approached problems of civility on campus and recent campus controversies over censorship, microaggressions, student protests, and the like. Elizabeth Corey criticized the policing of microaggressions on campus on the grounds that microaggressions are not only inherently subjective, but excessively subjective. As such, their regulation essentially undermines free inquiry necessary to a liberal education. I discussed my paper (coauthored with Clyde Ray) that explores microaggressions, trigger warnings, and safe spaces as well as recent campus controversies at Yale University, Middlebury College, and Evergreen State College through the lens of Plato's "democratic man." We describe these phenomena as demonstrating "teachers fearing their students" and seeking to appease them. Plato's discussion of regime decay offers the further warning that when a society has inculcated the democratic soul it is set to decline into tyranny. A trifecta of professors from Clark University (Robert Boatright, Kristen Williams, and Mark Miller) presented on their experience promoting free and civil discussion on campus through campus seminars on civil discourse exploring the history of free speech, media representations, and the like. The goal of their program is to provide students with the tools necessary for civil discourse. Rounding out the conference, Paul Corey used Teresa Bejan's recent book Mere Civility to discuss three conceptions of civility in the thought of Thomas Hobbes, John Locke, and Roger Williams and apply them to the university setting. He argued that while universities need free inquiry and the openness to different views such an orientation requires, they must also concern themselves with academic justice and with teaching virtues necessary to civil society.

The topics discussed are of enduring importance and no firm resolutions were reached by the end of the day. But whatever one thought of the relation between liberal arts education and political action, it became clear throughout the course of the sessions that sophisticated philosophical discussion of political ideas is essential both inside and outside the classroom.

\title{
Simulations And Games
}

\author{
Joseph W. Roberts, Roger Williams University
}

Simulations and games continue to be among the most impactful teaching practices that we can use to impart both substantive knowledge and useable skills to students. This is readily apparent in Victor Asal's "Gaming Levels of Analysis in International Relations Teaching" paper. It was easy to see how students could learn concepts and skills as the track participants played the games. Chris Silvia notes in his Journal of Public Affairs article "The Impact of Simulations on Higher-Level Learning" that simulations are most effective at forcing students "an opportunity to tackle ill-defined problems, for which there is no 'correct' answer, in a realistic setting." Similarly, Mary M. McCarthy concludes in his Journal of Political Science Education article "Role of Games and Simulations to Teach Abstract Concepts of Anarchy Cooperation and Conflict in World Politics" that "an active-learning exercise enhances student understanding of concepts and processes in world politics. This is whether it is an abstract game or a role-play simulation." While the literature is clear that the use of active learning techniques is effective, there are many issues that still remain. This 2018 TLC track attempted to recognize and evaluate several of those issues. Throughout the discussion, several themes emerged as particularly important for continued examination.

First, when designing and implementing simulations, it is important to understand fit for purpose. As John FitzGibbon and Erin Baumann in "All That You Can Leave Behind: Designing Simulations for Learning, Not Doing" explain, this simply means there is a need to make sure that the game or simulation fits the learning outcomes an instructor wants to accomplish, particularly in higher order thinking. Konrad Posch noted in "Play Your Role: A Policymaker 
Simulation to Ground East-Asian IR," some simulations are consensus building, others competitive, and others are more cooperative. While faculty need clear goals, they also need clear means of assessment. In "Lecture vs Simulations: Testing the LongTerm Effects," Adam Wunische does pretest, posttest, and delayed posttest to measure the effectiveness of simulations compared with lectures with the results showing that simulations were more effective. Michelle Allendoerfer, on the other hand, examined student retention of knowledge in "Do Simulations Improve Long-term Retention" and found unequivocal results. More research is needed to determine why the discrepancy between Wunische and Allendoerfer exists. Patricia Stapleton's "Knowledge Surveys as a Potential Assessment Tool of Simulation Course Outcomes," advocates for knowledge surveys, content-based questions that are sequenced in order in which the topics are presented in the course. Students take the survey and rank how confident they would be able to answer the question from 1 (low confidence) to 3 (high confidence) at different times in the semester/quarter. The results can be very important in measuring how well the simulations are working for students.

In the complementary papers "Learning by Experiencing: Improving Student Learning through a MUN Simulation" by Craig Albert and Augustine Hammond and "Assessing the Evidence in Support of Model UN" by Kelly Siegel-Stechler, the authors make it clear that large-scale simulations of international organizations can be particularly useful in developing the kinds of skills that employers say they want, including critical thinking, problem solving, and communication, among others. Finally, Elizabeth Radziszewski's manuscript, "WHACK Pack Cards and SCAMPER: Creativity-Building
Techniques for Effective Brainstorming," looks at specific software (SCAMPER) and a card game (WHACK Pack) to stimulate creativity, problem solving, and other learning outcomes. Depending on the learning outcomes, either of these tools can be used in multiple ways to engage students creatively. The adage for simulations bears repeating; there is always a need to reflect on the activities and why they are used and how they contribute to learning. Debrief is critical and cannot be overlooked.

Second, track participants believe that role assignment is critical to the efficacy of simulations. How should an instructor assign roles? Should it be random, allowing students to react to the role, or should it be assigned, allowing the instructor to control certain variables? Gretchen Knudsen Gee notes in "Classroom Simulations: Advantages and Challenges" that just playing a different role allows students to exercise critical thinking. Casey Delehanty and Ian Hopper ask an important question on this point in "The Pragmatic Simulation: An Interdisciplinary Simulation of the Austrian Succession." Is casting always crucial to making simulations work? Could the advantages of simulations be enhanced by more systematic role assignment decisions? Clearly, more work needs to be done to ask several important questions. Why would you choose one or another? How do you decide which method to use? Are all cases the same? For many simulations, if not all, diverse perspectives are important with the stated goal being to get students into unfamiliar places to enhance learning, critical thinking, and applying knowledge.

Third, frustration, emotional impact, or anxiety of students is something that all instructors must be aware of. Is it a deliberate outcome sought by instructor or is it unexpected? How dowe know when/where students are in the zone of proximal development? Sometimes things do not work as expected and students, and instructors, get frustrated by inefficiencies or failure. How do instructors and students deal with failure, in the sense of the simulation not working as expected? What happens when things do not work? Shawna Brandle's "Games, Movies, and Zombies: Making IR fun for Everyone" points out that not everything works as well as intended and flexibility is key but there is also an impact on student learning when it happens. Likewise, in "Board Games and Intro to IR" Petra Hendrickson built flipped classrooms that incorporated group discussion and games but found that the model failed spectacularly in all areas. Part of the problem might have been the free rider problem for group work and a disconnect between games for leisure and games for learning. It is useful fodder.

Finally, and perhaps most importantly, building a sense of classroom community before games or simulations is critical. Instructors must build a culture that makes the game or simulation possible (and hopefully successful) particularly for bigger projects. What is the community like? Some things will work with one group but not another. For example, Chad Raymond learned the hard way in "When Students Design their Own Games: A Failed Experiment in a First-Year Seminar" that freshman may not be good for game design work but could be better at actually playing a game. The track participants briefly did the same exercise as students in his course and were much more successful.

Collectively, we, as professors, need to critically examine why we do what we do in the classroom. Using instructional design principles will help us to be more effective in the classroom and will help our students become better learners.

\title{
Teaching Research, Writing, and Information Literacy
}

\author{
Delton T. Daigle, George Mason University \\ Austin Hofeman, George Mason University
}

In an environment of increasing uncertainty regarding facts, the importance of providing students with the skills to perform, analyze, and engage with research is increasingly critical, not just as political science practitioners but effective citizens. These methodological concerns go beyond familiarity with statistical procedures or analytical processes and extend to educating students on how to utilize a broad spectrum of skills to exercise critical skepticism in a data rich environment, and in so doing, clearly articulate one's arguments and conclusions. Imbuing students with the abilities to be effective political researchers as well as acute consumers of information was the primary focus of our track, with presenters highlighting important practices to engender student engagement with political science methods and connect these methodological approaches to increasingly relevant questions in civic life.

\section{INCREASING STUDENT ENGAGEMENT}

One of the more difficult challenges encountered by research methods courses involves stimulating student engagement with the material. 
While convincing students that statistical analysis is exciting is a daunting task, the larger concern of methodological courses should be on demonstrating to students the importance of being able to engage with research, critically assess sources, and understand what constitutes good or bad data and results. A broader focus on developing students' abilities to structure and present their own arguments and analysis should also be a clear focus on methodological instruction.

The political environment facing both instructors and students has increasingly necessitated a focus on helping students develop an ability to critically assess sources, data, and arguments. While developing students' abilities to conduct statistical tests or analysis is a core component of most methods courses, these abilities are incomplete without a complementary focus on assessing the quality of data and results. Bozovic's discussion, titled "Misuse Of Data As A Teaching Tool," regarding a clear focus on data literacy that does not replicate the entire research process but instead attempt to foster student recognition of poor data visualization and unsupported or incomplete arguments is highly important as a means to help inoculate future researchers from bad data and poor presentation. Similarly, Gabryszewska's summary of multiple methods to introduce a focus on source assessment (providing both internal and external resources for instructors), titled "Fake News: Tools For Teaching In An Era Of Misinformation," presents an opportunity to help students understand how messages can be constructed to appeal to different audiences and helps connect the content of methods courses to clear, realworld applications.

These skills must also be combined with a strong focus on allowing students to develop their writing abilities (which, in turn, can help them more cogently critique sources and data as well as more effectively present their own findings). A number of presentations in our track highlighted the importance of building courses overtly around providing multiple opportunities for students to write, revise, and review with instructors. DeLeon and Borck, in "Institutional Collaborations: An Innovative Approach To Writing Instruction In Political Science" and "Teaching Critical Thinking Through Reflective Writing In Political Science" respectively, explicitly recommend scaffolding writing assignments around revision opportunities and providing students with clear directives and clear criteria to help guide their writing.
DeLeon and Borck, along with Jenkins and Wiley in "'Start Writing Now'-An Analysis Of Student's Evaluations Of WritingIntensive Non-Writing Courses," also highlight the importance of placing writing assignments within the proper context, demonstrating to students the particular rhetorical requirements and assumptions within the field. Jenkins and Wiley undertake this contextualization a bit more directly, utilizing discipline-specific, small-cap courses that allow for a stronger focus for student attention and greater opportunities for feedback and review from instructors.

\section{TURNING ENGAGEMENT INTO PRACTICE}

The methodological curriculum provided to students can also benefit from being contextualized as applying beyond the realm of political science research. Demonstrating to students that the skills they are developing in these courses allow them to be more inquisitive and effective consumers of information and intersect with larger aspects of civic life can help foster a stronger sense of student engagement as well as a clearer rationale for the importance of these courses overall.

Providing students with the abilities to assess and present research should be coupled with a clear connection to real-world applications. The data and source assessment presentations discussed above help bridge this gap by demonstrating to students the consequences of poor data and argumentation, but this can still be somewhat abstract, especially when attempting to discuss the importance of understanding source motivations and biases. Oberle's historiographic approach in "Historiography And Fake News: Civic Engagement In The Political Science Classroom" seeks to combine the analytic skills highlighted by others as well as attempt to more clearly apply larger political science concepts (not just methodological concepts) to the real world. Such an approach allows for students to be exposed to multiple viewpoints and sources, tracing the development of historical understandings and allowing for the inclusion of factual and nonfactual sources for comparative purposes. Such an approach also enables instructors to discuss topics that interact strongly with students' own experiences and identities, further demonstrating the utility of a knowledge of political science overall.

This more hands-on and connected approach may help overcome some of the struggles presented by other presenters. Houck's discussion, titled "Critical Thinking
About Critical Thinking: Course-Embedded Research Into Politically Motivated Reasoning," of a capstone course intended to have students develop a stronger critical thinking ability through interaction with multiple examples of methods and a larger replication project demonstrates the importance of properly contextualizing assignments and working to continuously engage students in the processes of research. While Houck's class was clearly focused around the structural principles discussed above, students appeared to struggle with synthesizing research, structuring a literature review, and replicating experimental designs and analyses. While these replication skills are important to develop, the necessity of linking these assignments with practical applications cannot be understated. Similarly, Hutcheson, Boyd-Swan, and Nickels's focus in "Improving Confidence And Enhancing Engagement: Undergraduate Research Methods Teaching And Learning" on structure and organization is suggestive of a useful way to approach increasing student abilities on these assignments. Having a clear course shell that remains consistent across instructors and provides clearer expectations and a more drawn-out process can help more effectively achieve learning outcomes. Hutcheson, Boyd-Swan, and Nickels also highlight the benefits of structuring courses to be more mindful of nonmajors, though this may conflict with the benefits of the tighter contextual focus raised by others.

\section{CURRICULUM DESIGN AND STRUCTURE}

The importance of fostering engagement and connecting course content to larger abilities requires instructors to be mindful of how coursework is structured. Connecting methodological lessons to more abstract skills of analysis or critical thinking also requires hands-on practice to be effective; students must learn the how as well as the why to truly understand the utility of developing critical thinking and analytical muscles. The importance of building time into courses for students to fully engage with the assignments required of them was consistently discussed as part of our track, as was the necessity of structuring courses and assignments in a way that allowed students to review and reassess their work, further demonstrating how to produce better research overall. This concern regarding clearer structuring intersects with a larger question of course contentunderstanding what is (and, perhaps more importantly, what is not) being provided in 
political science methods courses across institutions is crucial, as assimilating effective practices will be of limited success if particular aspects of an institution's curriculum differ from other institutions. This may require a more holistic or widespread assessment of what is being provided in political science methods courses, with a long-term focus on developing a more consistent approach that can successfully integrate the suggestions made here.

The benefits of a more drawn-out process are demonstrated clearly in Zettl \& Nikolopoulos's exploration of a two-stage structure, titled "The Humboldtian Ideal Of Higher Education: Undergraduate ResearchBased Learning In Political Science," providing general themes and a more interdisciplinary approach in students' first years with an individual research project in the final year. Such an obligatory and divided approach seemed to be effective in developing students' overall skills as well as allowing them to trace their own process-though the division may lead to some selection bias, as students who come back for the research project will likely be more interested overall. Similarly, Sanborn in "A Reflection On Methods And A Method Of Reflection" combines many of the approaches discussed above, going in depth on topics and working to keep students continuously engaged and motivated throughout the semester. Having students reflect on the material outside of class facilitated greater engagement during and (more importantly) between class meetings and allowed students to better draw connections between components of the material across the semester.

This focus on student engagement, understanding of the practical applications of methods, and structure must recognize that different institutions take different approaches to curriculum design overall. The findings presented by Daigle, Hofeman, and Neulen in "Comparing Undergraduate Methods Across America: Results From A Random Sample" find large amounts of consistency in course material, though some significant differences that may undermine the application of some of the practices discussed above. Differences in lab components and software utilization are likely more a function of department resources, though findings regarding differences across course sequence designs (single/multiple, required/elective) should interact with the structure and scaffolding discussions above to better integrate material and better facilitate student interactions and abilities. These differences, along with the more expansive approaches suggested by Gabryszewska and DeLeon, may be useful as a starting point for a larger discussion regarding methods curriculum and the best means to provide both a methodological familiarity and a larger critical ability.

\section{FINAL THOUGHTS ON OUR TRACK}

Effective civic engagement requires important abilities of analysis and criticism, as well as an understanding of cogent presentation of argument and results. Providing students with the skills necessary to produce clear research and to grapple with issues of invalid information or poorlypresented data is a core responsibility of political science educators. The presentations discussed above have raised a number of intriguing and effective ways to approach maximizing student engagement with the material and processes of political science research, which furthers the larger goal of endowing students with critical-thinking skills. Understanding how to identify good sources, good data, and good conclusions will only grow in importance as students face an increasingly information-dense society, making the tasks of providing students with the abilities to engage with this society in a meaningful and efficacious way even more important going forward. The practices and approaches employed by participants in our track provide crucial guides to ensuring success in teaching political science students a variety of methodological techniques. As important as that basic pedagogical goal is, it also became clear from all the scholars mentioned above, as well as the nonpresenting participants, was that data and research literacy is an essential skill for students to develop to become better informed and engaged citizens.

\section{The Virtual and Technology Enhanced Classroom}

\section{Tiffany Bohm, Lake Michigan College}

The Virtual and Technology Enhanced Classroom track at the 2018 APSA Teaching and Learning Conference addressed a wide variety of topics which included online teaching, innovative techniques, and unique pedagogical models, all focused on improving engagement.

Given the current climate of political affairs engagement in political science courses, this may not appear to be an overwhelming challenge. Yet, large lecture seminars and Massive Open Online Courses (MOOC) pose different issues for faculty. During the morning segment of the track, panelists focused on online teaching techniques, simulations, assessments, and student use of technology in the online classroom.

Marcella Morris of Emory University suggested that students may be more interactive in a MOOC when external links and sources are made available. By providing news web links and videos, students were more engaged in the class as measured by their online posts or responses. Moreover, the increased online interaction advanced discussion wherein politically neutral responses encouraged other students to participate. In light of the partisan environment, this is noteworthy as a fair-minded option to not only encourage class engagement, but also improve civic discourse.

Encouraging better communication and diplomacy can also be achieved through online simulations. Jennifer Schiff from Western Carolina University followed Morris and presented a comprehensive curriculum design for teaching Model United Nations in an online classroom. Schiff used an "IR Model" introduced by J. Simon Rofe in his European Political Science article "The 'IR
Model': A Schema for Pedagogic Design and Development in International Relations Distance Learning Programmes" and presented the course material using the Watch-ReadInteract-Submit (WRIS) method. Her positive experience using this design allowed peer-to-peer learning as well as established consistency in assessments, both integral assets to successfully increasing student engagement.

In addition to facilitating MOOCs with several hundred students or including simulations in an online classroom, teaching political science is very dynamic. This is no more evident than in teaching quantitative skills through an online learning management system like Canvas or Blackboard. Sarah O'Byrne from Johns Hopkins University addressed how using discussion boards creatively and inspiring collaboration can 
increase student engagement in an often challenging skill area. By presenting a problem and allowing students to work together in groups using a discussion thread where screen sharing or other modes of access are used, students who are geographically dispersed can learn asynchronously.

Following the presentations about online teaching, the track moved to assessment tools in online classrooms. From a discipline or program-level analysis, Nanette Levinson from American University examined how innovations may impact international affairs education. Currently, 37 schools offer professional master's degree programs in international affairs and media attention has increased the growth of such programs, specifically with study abroad and online campus internationalization initiatives. She proposed a "Change Logic Approach" to assess international affairs education and highlighted a new evaluation resource distributed by the W.K. Kellogg Foundation in November 2017. This new approach focuses on non-linear, interactive analysis, community needs, assets paths to program development, and desired results as far as outcomes and impact.

The next presentation from Lauren Elliott-Dorans at Ohio University evaluated laptop or computer use in her classes. Previous research by Daniel M. Oppenheimer in "The Pen Is Mightier Than the Keyboard" suggests that students who take notes by hand have better retention and ElliottDorans tested these findings by randomly assigning a laptop ban over two semesters at a four-year public university, similar to previous research by Kenneth A. Kiewra in 1989. Elliott-Dorans's findings suggest that banning laptops may encourage student absences and may result in students doing worse than those with laptops on the final exam. Conversely, students in Elliott-Dorans's classes performed better when they were allowed to use their technology. She concluded that we may be at the cusp of a generational shiftyoung people do better multitasking with technology and older learners may struggle with adapting to the use of it.

At the end of this session, the issue of plagiarism was addressed by Barbara Morazzani, DeMontfort University. Morazzani addressed the varied faculty responses to plagiarism and allegations of plagiarism by evaluating how plagiarism is defined. Students and faculty differ in their understanding of the issue and how it is defined which may lead to a need for institutional policies or perhaps even consensus on regulation. At present, discussion of legal considerations for drafting or executing plagiarism policies as well as enforcing these policies may be necessary in higher education.

In the afternoon session of the track, two panelists introduced innovative tools to facilitate instruction. One was introduced by Eric Loepp from the University of Wisconsin, Whitewater. Loepp uses active learning pedagogy to engage his students and supplements traditional technology with Spark. Spark is a pilot program from Cisco that enables remote learning, shared "spark" space for collaboration, shared documents, and Voice Over Internet Protocol (VOIP) technology that not only allows for personalized learning units, but also documents all course proceedings for increased accessibility. This accessibility provides students with an informal engagement platform like popular social media websites and provides instructors with a method for monitoring student communication. Loepp highlighted three main drawbacks. First, Spark was quite expensive and may be cost-prohibitive for smaller institutions. Second, the students have around-the-clock access to the instructor and Loepp recommends instructors create virtual walls so students know when collaboration hours are as well as office hours for the instructor. Finally, Spark does not currently integrate with any learning management system.

Eric Myers from West Virginia University introduced Virtual Learning Reality as he utilized it to bolster empathy and social capital. By using Virtual Reality (VR) goggles, Myers assigned students videos to watch on cell phones. The videos provided a 360 degree real-world view of a location or an event related to international relations and Myers is currently analyzing how these videos may improve levels of empathy. Similar to the Spark technology, there are some drawbacks to using VR goggles in the classroom. While the goggles are inexpensive, some students may not have enough space to download the videos on a phone or other students may not have a smartphone and a loaner will need to be provided. Additionally, some students may experience dizziness or other temporary side effects after watching a video. Myers noted that the challenge for faculty wishing to use VR technology is to fully integrate the videos within the context of the course to receive the greatest impact.

The final session of the track included three presentations where each panelist used a different method in an effort to encourage civic engagement outside of the classroom with online or technological tools. Judithanne
Scourfield McLauchlan from the University of South Florida, St. Petersburg, uses a statemandated state government online course to encourage civic engagement by assigning three projects throughout the semester. While some faculty may find it hard to get students in an online class to participate in an external activity, McLauchlan has been quite successful with her model that enables the students to select something that not only interests them, but also fits within their personal schedules. Students have participated in council meetings, attended public forums with local representatives, and conducted online research or politically informed projects using the internet. In teaching ten sections of the course, McLauchlan finds that students self-disclose they know more about how government works and that while many did not look forward to the projects, at the end of the course appreciated having completed them.

After McLauchlan, Daniel Oross, a Fulbright Scholar from Hartwick College, presented on gamification from a comparative perspective. Oross evaluated how an American college experience could be replanted into civic education of a newly formed democracy. By using iCivics, a website founded by former US Supreme Court Justice Sandra Day O'Connor, students can play various games designed to foster civic engagement. Oross suggests that while playing online games may enhance participation, they may not promote deliberative decision making without instructional practices as indicated by Blevins, LeCompte and Wells in "Innovations in Civic Education: Developing Civic Agency Through Action Civics." The ideas Oross presented are innovative and highlight the need for additional research into the effects of gamication on levels of student civic engagement.

The final presenter of the day, Tiffany Bohm, presented an in-progress research initiative using several software programs to flip the political science classroom. The flipped classroom pedagogy highlights student learning with the faculty member serving as a facilitator role for content delivery. While this type of project or problem-based learning has been in the K-12 classrooms since the early 200os, it is slowly making its way into higher education. With a 50 million dollar renovation project on-going at Lake Michigan College and the increased use of personal technology, Bohm is using several software programs to gauge student engagement which in turn may or may not drive increased levels of civic engagement. 
These programs include TopHat and Kaltura used alongside Zoom for online collaboration. During the fall 2018 midterm election, Bohm will use data from the National Study of Learning, Voting, and Engagement (NSLVE) to evaluate if the increased use of technology had any effect on voter registration and voter turnout.

\section{TLC at the 2018 Annual Meeting}

As part of the 2018 Annual Meeting in Boston, APSA will be hosting "TLC at APSA" on Saturday, September 1, 2018. This full-day mini-conference seeks to provide an interactive forum for scholars to share tools for political science education and research on the scholarship of teaching and learning. You may confirm your attendance at the miniconference when registering for the APSA Annual Meeting. 